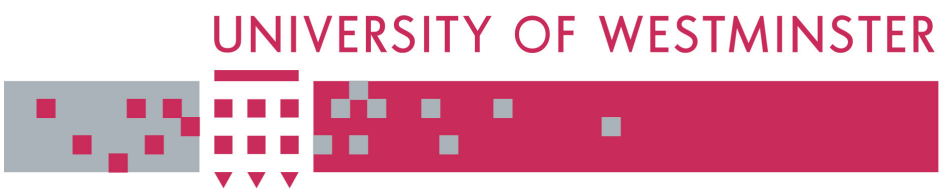

WestminsterResearch

http://www.wmin.ac.uk/westminsterresearch

\title{
An optically reconfigurable dual-band branch-line coupler with artificial transmission lines
}

Drasko Draskovic

Djuradj Budimir

School of Informatics

Copyright (C) [2008] IEEE. Reprinted from the 2008 IEEE Antennas and Propagation Society International Symposium, Jul 5-11, 2008, San Diego, California. IEEE, Los Alamitos, USA, pp. 1-4. ISBN 9781424420414.

This material is posted here with permission of the IEEE. Such permission of the IEEE does not in any way imply IEEE endorsement of any of the University of Westminster's products or services. Personal use of this material is permitted. However, permission to reprint/republish this material for advertising or promotional purposes or for creating new collective works for resale or redistribution to servers or lists, or to reuse any copyrighted component of this work in other works must be obtained from the IEEE. By choosing to view this document, you agree to all provisions of the copyright laws protecting it.

The WestminsterResearch online digital archive at the University of Westminster aims to make the research output of the University available to a wider audience. Copyright and Moral Rights remain with the authors and/or copyright owners.

Users are permitted to download and/or print one copy for non-commercial private study or research. Further distribution and any use of material from within this archive for profit-making enterprises or for commercial gain is strictly forbidden.

Whilst further distribution of specific materials from within this archive is forbidden, you may freely distribute the URL of the University of Westminster Eprints (http://www.wmin.ac.uk/westminsterresearch).

In case of abuse or copyright appearing without permission e-mail wattsn@wmin.ac.uk. 


\title{
An Optically Reconfigurable Dual-Band Branch-Line Coupler with Artificial Transmission Lines
}

\author{
D. Draskovic and D. Budimir \\ Wireless Communications Research Group, University of Westminster, \\ 115 New Cavendish Street, London W1W 6UW, United Kingdom \\ Email: d.budimir@wmin.ac.uk
}

\section{Introduction}

Over the past few years, branch-line coupler designs with bandwidth enhancement and size-reduction have been gaining favor. Recently, the interest in tunable microwave components, such as couplers, baluns, phase-shifters, filters has arisen. Tuning techniques include varactor/pin diodes, RF MEMS, ferroelectrics and optical tuning. The use of pin and varactor diodes has many disadvantages such as high loss, high power consumption, unacceptable SNR and distortion of the incident signals. RF MEMS provide a better solution in building tunable passives, which are necessary for multiband systems. These passives are small, with low insertion loss, high Q and low power consumption, they introduce less signal distortion, but the fastest tuning speeds are around a microsecond. Ferroelectric materials have fast tuning speeds ( picoseconds). They are easily tuned by voltage only. The main disadvantage and the problem is high level dielectric losses. The advantages of the optically controlled microwave devices include high isolation between the controlling optical beam and the controlled microwave signal, short response time, high-power handling capacity, immunity to electromagnetic interference and low cost. Optically controlled antennas [1], filters [2], resonators [3], phase-shifters [4], have been demonstrated recently. More recently, we presented the design of optically reconfigurable dual-band branch-line coupler [5].

In this paper, reconfigurable, optically tuned dual-band branch-line couplers will be realized using artificial transmission lines and photoconducting switches. Artificial transmission lines shown in [6] give excellent results when applied to the coupler design. This design gives size reduction compared to the design presented in [5]. Tunability is achieved by increasing the power of the laser applied to the highly resistive silicon wafer and changing the properties of silicon under optical illumination. This approach has many advantages: high-speed switching, electromagnetic transparency (no interference) and thermal and electrical isolation between the coupler and the control circuit.

In terms of fabrication complexity, the device presented in this paper could be compared to varactor tuned devices. However, many varactor based designs require biasing lines and short circuit vias.

\section{Circuit Design}

The architecture of a dual-band coupler is shown in Figure 1. The artificial transmission lines (ATL1 and ATL2) are composed of microstrip quasilumped elements and their discontinuities [6]. Using this approach, transmission lines with different values of characteristic impedances and electrical lengths can be synthesized. The physical length 
of a transmission line is reduced, while preserving its electrical properties. Our coupler design proposed in [5] is significantly miniaturized using ATLs. Characteristic Impedances and electrical lengths of the transmission lines are presented in Table 1. Figure 2 shows the results for the OFF $(0 \mathrm{~mW})$ and ON $(200 \mathrm{~mW})$ states of the switch, respectively. The artificial transmission line and the equivalent circuit of the switch are shown in Figure 3. The Rogers Duroid 5880 substrate with thickness of $h=0.508$ $\mathrm{mm}$ and dielectric constant $\varepsilon \mathrm{r}=3.38$ was used for the design.

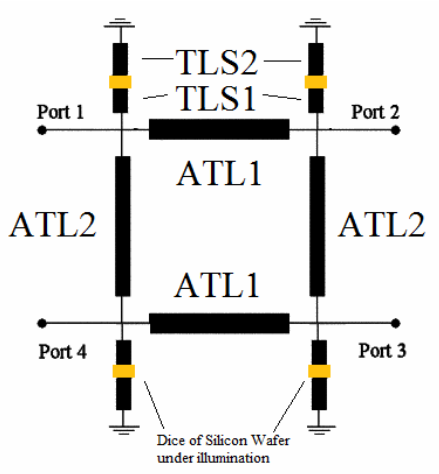

Fig. 1. Circuit Design.

\begin{tabular}{|c|c|c|}
\hline & Impedance ( $\mathbf{\Omega})$ & $\begin{array}{l}\text { Electrical Length } \\
\text { (degrees) }\end{array}$ \\
\hline ATL1 & 42.7 & $\mathrm{E}=90$ \\
\hline ATL2 & 60.2 & $\mathrm{E}=90$ \\
\hline TLS1 & 54.4 & $E=75.6$ \\
\hline TLS2 & 54.4 & $E=27$ \\
\hline
\end{tabular}

Table 1. Characteristic Impedances and electrical lengths of the transmission lines.



Fig.2. Magnitude response for the OFF and ON states of the optical switch. 


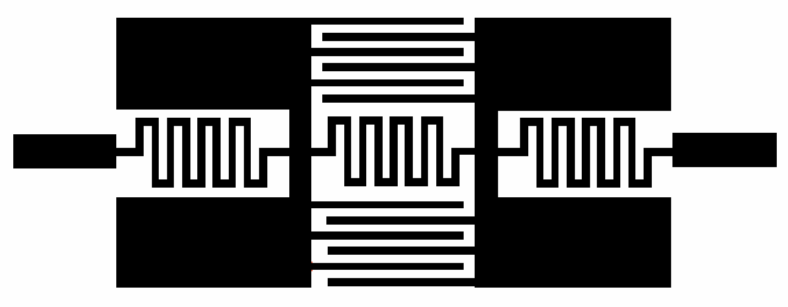

Fig.3. ATL and coupler layout.

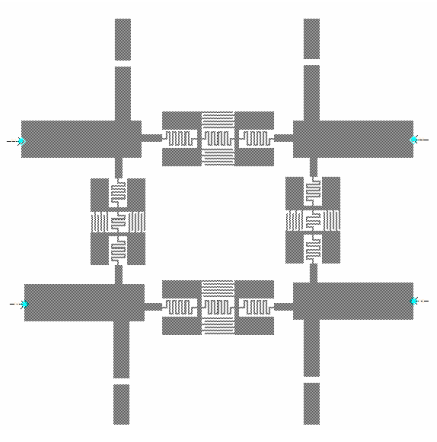

\section{Simulation Results}

The simulated scattering parameter input and output port responses (magnitude response) for two states of the switch $(0 \mathrm{~mW}$ and $200 \mathrm{~mW})$ are shown in Figure $4 \mathrm{a}$ and $4 \mathrm{~b}$ respectively. Good reflection is shown in both frequency bands (better than $-20 \mathrm{~dB}$ ). The coupling is at $-3 \mathrm{~dB}$. Figure 5 shows the phase differences between output ports 2 and 1 (90 degrees) in both bands. The phase imbalance is less than 0.5 degrees.
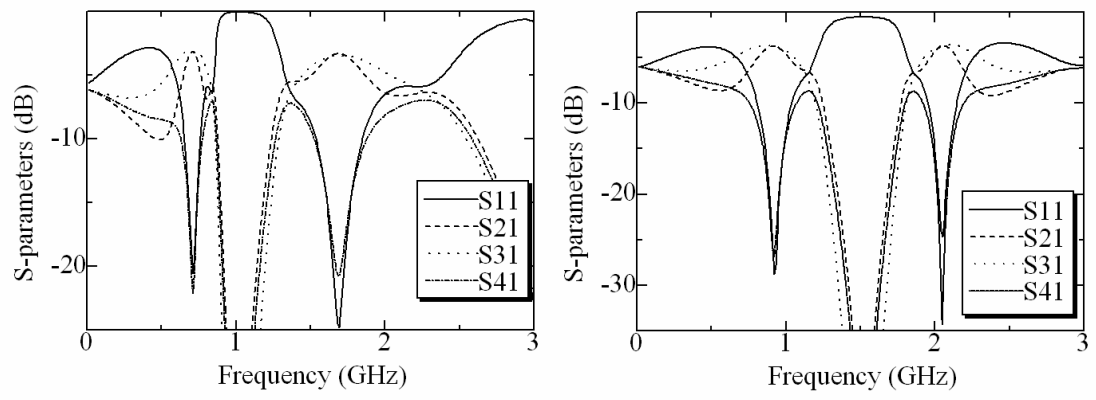

Fig.4. Simulated magnitude output ports responses.
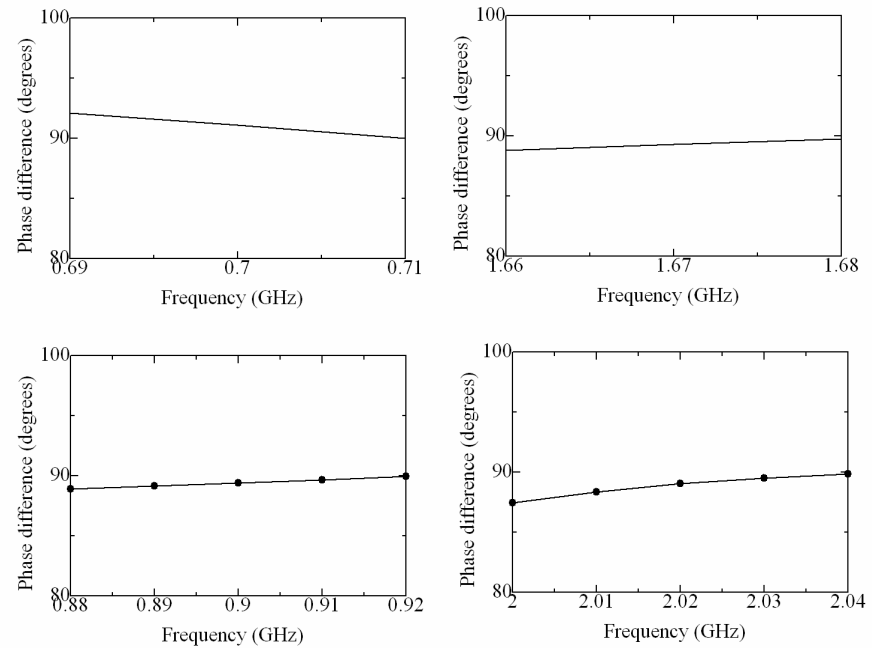

Fig.5. Simulated phase difference between the output ports in both bands (phase $(2,1)$-phase $(3,1))$. 


\section{Conclusion}

The frequency shift of 30\% has been achieved from all switches off to all switches on in both frequency bands. The advantages of this approach are high-speed switching, electromagnetic transparency (no interference) and thermal and electrical isolation between the coupler and the control circuit. The use of the artificial transmission lines significantly decreased the overall size of the circuit.

\section{References}

[1] C. J. Panagamuwa, A. Chauraya, and J. C. Vardaxoglou, "Frequency and beam reconfigurable antenna using photoconducting switches," Antennas and Propagation, IEEE Transactions on, vol. 54, pp. 449-454, 2006.

[2] A. Chauraya, J. Kelly, R. D. Seager, and J. C. Vardaxoglou, "Frequency switchable microstrip filter for microwave frequencies," presented at European Microwave Conference, 20052005.

[3] G. Zouganelis and D. Budimir, "Silicon gap-loaded microstrip slit-tetragonal resonator under IR-irradiation," in Microwave and Optical Technology Letters. vol. 49, 2007, pp. 699-702.

[4] M. El Khaldi, F. Podevin, and A. Vilcot, "Optically controlled phase-shifter based on gaps on microstrip line," 2003.

[5] D. Draskovic and D. Budimir, "Optically Reconfigurable Dual-Band Compact Branch-Line Coupler", European Conference on Antennas and Propagation, November 11-16, 2007, Edinburgh, UK.

[6] C. W. Wang, T. G. Ma, and C. F. Yang, "A New Planar Artificial Transmission Line and Its Applications to a Miniaturized Butler Matrix," Microwave Theory and Techniques, IEEE Transactions on, vol. 55, pp. 2792-2801, 2007.

[7] K. K. M. Cheng and W. Fai-Leung, "A novel approach to the design and implementation of dual-band compact planar 90deg branch-line coupler," Microwave Theory and Techniques, IEEE Transactions on, vol. 52, pp. 2458-2463, 2004.

[8] E. E. Djoumessi, E. Marsan, C. Caloz, M. Chaker, and K. Wu, "Varactor-Tuned Dual-Band Quadrature Hybrid Coupler," Microwave and Wireless Components Letters, IEEE, vol. 16, pp. 603-605, 2006. 